\title{
Quality Evaluation of Olive Oil by Statistical Analysis of Multicomponent Stable Isotope Dilution Assay Data of Aroma Active Compounds
}

\author{
Georg Dierkes, ${ }^{\dagger}$ Annette Bongartz, ${ }^{\dagger}$ Helmut Guth, ${ }^{\dagger}$ and Heiko Hayen* ${ }^{\dagger}$ \\ ${ }^{\dagger}$ Department of Food Chemistry, University of Wuppertal, Wuppertal, Germany

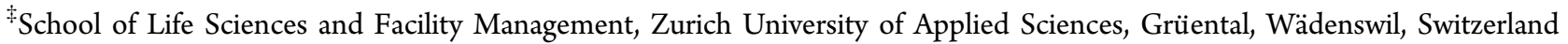

Supporting Information

ABSTRACT: An instrumental method for the evaluation of olive oil quality was developed. Twenty-one relevant aroma active compounds were quantified in 95 olive oil samples of different quality by headspace solid phase microextraction (HS-SPME) and dynamic headspace coupled to GC-MS. On the basis of these stable isotope dilution assay results, statistical evaluation by partial least-squares discriminant analysis (PLS-DA) was performed. Important variables were the odor activity values of ethyl isobutanoate, ethyl 2-methylbutanoate, 3-methylbutanol, butyric acid, E,E-2,4-decadienal, hexanoic acid, guaiacol, 2-phenylethanol, and the sum of the odor activity values of Z-3-hexenal, E-2-hexenal, Z-3-hexenyl acetate, and Z-3-hexenol. Classification performed with these variables predicted $88 \%$ of the olive oils' quality correctly. Additionally, the aroma compounds, which are characteristic for some off-flavors, were dissolved in refined plant oil. Sensory evaluation of these models demonstrated that the off-flavors rancid, fusty, and vinegary could be successfully simulated by a limited number of odorants.

KEYWORDS: olive oil, sensory quality, stable isotope dilution assay, headspace solid phase microextraction, partial least-squares discriminant analysis

\section{INTRODUCTION}

The rising olive oil consumption outside the Mediterranean area can be explained due to the health benefits attributed to olive oil, basically by its specific odor and taste characteristics. ${ }^{1}$ It is therefore not surprising that the quality of olive oil is determined primarily by its sensory properties. Sensory evaluation is based on the so-called "Panel Test" developed by the International Olive Council. ${ }^{2}$ This procedure, if performed by well-trained panelists, gives good and reproducible results, which are comparable with those of other panels. However, there are still disadvantages in the sensory quality evaluation. These are (i) the lack of stable and standardized reference oils for the different off-flavors and (ii) the large number of panelists that is needed for statistically confirmed results. ${ }^{3}$

Several instrumental methods have been developed as alternatives to sensory methods to evaluate the quality of olive oil. Many authors identified the important aroma active compounds in olive oil even in those with different off-flavors. Two review papers summarize the scientific findings. ${ }^{4,5}$ Headspace solid phase microextraction (HS-SPME) was found as the best method for the aroma analysis of olive oil. ${ }^{6}$ However, this method only gives exact quantification results if recovery rates and response factors are determined for each compound, which was not carried out in most studies. These disadvantages of using external calibration can be circumvented by application of stable isotope dilution assay. ${ }^{7}$ Exact quantification data are needed for the calculation of odor activity values and therefore for the assessment how important an aroma active compound is for the overall flavor. Correlation of sensory data with quantification results was made by some authors, ${ }^{8,9}$ but not on the basis of odor activity values. Quality evaluation was based upon compounds such as ethyl acetate, ethanol, or octane, ${ }^{10}$ which have relatively high odor thresholds. Therefore, they are unlikely to be responsible for the detected off-flavors. These drawbacks in the recently described methods are pointed out by Garcia-González and Aparicio in a perspective paper. ${ }^{3}$

For these reasons an instrumental method for the evaluation of olive oil quality, which is based on quantitative results of aroma active compounds and multivariate data analyses, was developed. For this purpose, 95 olive oil samples of different qualities were analyzed. After identification of the important odorants for the positive and negative attributes of the olive oil flavors, these compounds were quantified by headspace solid phase mircroextraction-gas chromatography with mass selective detection (HS-SPME-GC-MS). Selection of the odor active compounds was based on their odor thresholds, odor quality, and their relevance for the olive oil aroma described in the literature. Mathematical models for the prediction of olive oil quality were computed on the basis of the quantitative results based on stable isotope dilution assays and calculated odor activity values (OAVs, ratio of concentration to odor threshold) of important odorants. Additionally, aroma models for the offflavors "rancid", "musty", and "fusty" were prepared by dissolving aroma compounds in refined plant oil in the concentrations found in several oil samples. These model mixtures were also evaluated by a sensory panel.

Received: August 24, 2011

Revised: November 21, 2011

Accepted: November 26, 2011 


\section{MATERIALS AND METHODS}

Chemicals. The following compounds were obtained commercially: 1-5, 7, 8, 10-18, 20-24 (odorants from Table 2) (Aldrich, Steinheim, Germany); $\left[{ }^{13} \mathrm{C}\right]_{2}$-acetic acid, $\left[{ }^{13} \mathrm{C}\right]_{2}$-ethyl acetate, $\left[{ }^{13} \mathrm{C}\right]_{2^{-}}$ acetone, and $\left[{ }^{2} \mathrm{H}\right]_{3}$-ethanol; $\left[{ }^{2} \mathrm{H}\right]_{6}$-dimethyl sulfate, lithium aluminum deuteride, 2-hexyn-1-ol, 3-hexyn-1-ol, 2-octyn-1-ol, 2-nonyn-1-ol, 3,7dimethyl-1-octanol, (methoxycarbonylmethylene)triphenylphosphorane, $\left[{ }^{2} \mathrm{H}\right]_{2^{-}}$dichloromethane (Sigma-Aldrich, Steinheim, Germany); deuterium gas 2.7 (Air Liquide, Krefeld, Germany), dilithium tetrachlorocuprate $0.1 \mathrm{M}$ solution in THF, and allylmagnesium bromide $1 \mathrm{M}$ solution in diethyl ether (Acros Organics, Geel, Belgium). Silica gel 60 (Merck) was treated with $\mathrm{HCl}^{11}$ and dried to a water content of $1.5 \%$ by mass.

SPME Fiber. An SPME fiber (length $1 \mathrm{~cm}$ ) coated with 50/30 $\mu \mathrm{m}$ polydimethylsiloxane/divinylbenzene/Carboxen phase (Supelco Ltd., Bellefonte, PA) was used. Before use, the fiber was conditioned by introducing it into the injector of the gas chromatography system set at $260{ }^{\circ} \mathrm{C}$ for $2 \mathrm{~h}$ in a stream of helium.

Olive Oils. Ninety-five olive oil samples were from different countries (22 Italy, 34 Spain, 22 Greece, 3 Portugal, 3 Israel, 3 Turkey, 2 Croatia, 2 Saudi Arabia, 1 Morocco, 1 Australia, 1 Slovenia, and 1 Jordan). The oil samples were stored at $-20{ }^{\circ} \mathrm{C}$ until use.

Sensory Analyses. Sensory evaluations were performed by the Swiss Olive Oil Panel (expert olive oil panel of the Zurich University of Applied Sciences) consisting of at least 8-10 assessors. All oils were subjected to an extended panel test as reported in the annex of EU Regulation 640/2008, as well as the IOC's instructions for the objective assessment of olive oils (COI/T.20/Doc.No.15/Rev.3). From the 95 oil samples, 64 were classified as "extra virgin" (defects = 0 , fruityness $>0$ ). Of the remaining 31 sample, 30 were classified as "virgin" (defects $\leq 3.5$ ) and 1 as "lampante" (defects $>3.5$ ). The oils had different off-flavors (5 fusty, 5 musty, 20 rancid, 1 other).

Preparation of Aroma Model Oils. The aroma compounds listed in Table 4 were dissolved in refined rapeseed oil. The four aroma model oils with the off-flavors rancid, fusty, and vinegary were mixed by resolving aliquots containing the odorants in the amounts listed in Table 4 in $1 \mathrm{~L}$ of refined rapeseed oil.

Vacuum Distillation. The volatile fractions of selected olive oil samples were isolated by high-vacuum distillation as described previously. ${ }^{12,13}$ The oil sample $(500 \mathrm{~g})$ was diluted with diethyl ether $(1: 1, \mathrm{v} / \mathrm{v})$. The volatile compounds were stripped off together with the solvent in high vacuum $\left(p=10 \mathrm{mPa} ; T=40{ }^{\circ} \mathrm{C}\right)$. The condensate obtained was concentrated to $200 \mu \mathrm{L}$ on a Vigreux column $(50 \times$ $1 \mathrm{~cm}$ ) followed by microdistillation.

High-Resolution Gas Chromatography-Olfactometry (HRGC-O). Identification of 21 aroma active compounds was performed by HRGC-O. One microliter of the concentrated vacuum distillate was injected into a Trace ultra gas chromatograph (Thermo Scientific, Dreieich, Germany) equipped with a Phaser sniffing port (ATAS GL International BV, Veldhoven, The Netherlands) and FID and analyzed on capillary DB-FFAP $(30 \mathrm{~m} \times 0.32 \mathrm{~mm}, 5 \mu \mathrm{m}$ film thickness). Initially, the temperature of $35^{\circ} \mathrm{C}$ was held for $2 \mathrm{~min}$, then raised by $40{ }^{\circ} \mathrm{C} / \mathrm{min}$ to $60^{\circ} \mathrm{C}$, and held isothermally for $5 \mathrm{~min}$; subsequently, the temperature was raised by $8{ }^{\circ} \mathrm{C} / \mathrm{min}$ to $230{ }^{\circ} \mathrm{C}$ and finally held at $230{ }^{\circ} \mathrm{C}$ for $10 \mathrm{~min}$. The injector and detector temperatures were set to $240{ }^{\circ} \mathrm{C}$.

HS-SPME Analysis. A $1.3 \mathrm{~g}$ sample spiked with $1 \mu \mathrm{L}$ of internal standard mixture was placed in a $125 \mathrm{~mL}$ headspace vial fitted with a silicone septum. After an equilibration time of at least $5 \mathrm{~min}$, SPME sampling was performed by exposing the fiber for $30 \mathrm{~min}$ in the headspace of the sampling at $50{ }^{\circ} \mathrm{C}$ under magnetic stirring. The fiber was then desorbed in an Optic 3 programmable temperature injector (Atas GL International, Eindhoven, The Netherlands). The injector temperature at the beginning was $35{ }^{\circ} \mathrm{C}$, then raised by $20{ }^{\circ} \mathrm{C} / \mathrm{s}$ to $240^{\circ} \mathrm{C}$, and held isothermally for $12 \mathrm{~min}$. The split valve was opened after $2 \mathrm{~min}$ (split flow $=10 \mathrm{~mL} / \mathrm{min}$ ). For reconditioning, the SPME fiber was left for $12 \mathrm{~min}$ in the hot injector.

HRGC-Mass Spectrometry (MS). The MS system DSQ II (Thermo Scientific, Dreieich, Germany) was used in combination with a Trace ultra GC (Thermo Scientific, Dreieich, Germany). Compound identification was performed in the electron impact mode (EI-MS) at $70 \mathrm{eV}$. Quantification was performed in the chemical ionization mode (CI-MS) at $120 \mathrm{eV}$ using methane as the reagent gas $(2 \mathrm{~mL} / \mathrm{min})$. Soft ionization in $\mathrm{CI}$ mode assured no loss of labeling by fragmentation of the molecules. Chromatographic separation was performed on a FFAP capillary (30 m $\times 0.25 \mathrm{~mm}, 0.25 \mu \mathrm{m}$ film thickness). Only the compounds 6, 9, 19, and 20 were quantified using an OV-1701 capillary ( $30 \mathrm{~m} \times 0.25 \mathrm{~mm}, 0.25 \mu \mathrm{m}$ film thickness) by EI-MS at ionization energy of $70 \mathrm{eV}$. Fragment ions containing the labeling were detected for these compounds even with hard ionization in EI mode. Quantitative assessment of volatile compounds was carried out by analyzing the ions listed in Table 2. MS response factors were determined by analyzing mixtures of known amounts of labeled and unlabeled compounds in different mass ratios (1:5 to 5:1). The ratios of the peak areas of the labeled standards and of the analytes were plotted against the concentration ratios. The plots gave straight lines showing linearity in the observed range of area ratios, whereas slopes represent response factors (Table 2). Concentrations were calculated from the peak areas obtained from the mass chromatograms using the equation

$$
C=\frac{m_{\text {labeled }}}{m_{\text {sample }}} \times \frac{A_{\text {unlabeled }}}{A_{\text {labeled }}} \times \mathrm{rf}
$$

where $C=$ concentration, $m_{\text {sample }}=$ mass of the olive oil analyzed, $m_{\text {labeled }}=$ amount of internal standard added $A_{\text {unlabeled }}=$ area counts for analyte, $A_{\text {labeled }}=$ area counts for internal standard, and $\mathrm{rf}=$ response factor.

Dynamic Headspace Analysis. Compounds 22-24 were quantified using the dynamic headspace autosampler PTA3000 (IMT, Moosbach, Germany). A $200 \mathrm{mg}$ sample spiked with known amounts of $\left[{ }^{13} \mathrm{C}\right]_{2}$-acetone, $\left[{ }^{13} \mathrm{C}\right]_{2}$-ethyl acetate, and $\left[{ }^{2} \mathrm{H}\right]_{3}$-ethanol was placed in a $25 \mathrm{~mL}$ headspace vial fitted with a silicone septum. The volatile compounds were stripped off for $5 \mathrm{~min}$ at $40^{\circ} \mathrm{C}$ with helium as purge gas $(10 \mathrm{~mL} / \mathrm{min})$. Refocusing was performed in the Tenax trap at $-110{ }^{\circ} \mathrm{C}$. HRGC-MS was performed on the system described above using a FFAP capillary $(30 \mathrm{~m} \times 0.25 \mathrm{~mm}, 0.25 \mu \mathrm{m}$ film thickness) and EI-MS at $70 \mathrm{eV}$. Quantitative assessment of volatile compounds was carried out by analyzing the ions listed in Table 2 .

MS response factors were set to 1 , because these compounds were obtained commercially (99 atom $\%{ }^{13} \mathrm{C}$ and 99 atom $\%{ }^{2} \mathrm{H}$, respectively). Concentrations were calculated as described above.

Synthesis. The synthezised internal standards used for HS-SPMEGC-MS were labeled with deuterium.

The following deuterated standards were synthesized according to the literature cited: $d-1, d-2, d-4, d-6, d-8, d-10, d-11, d-21 ;^{14} d-12$, d-15. ${ }^{15}$

The esters $d-3$ and $d-19$ were synthesized analogously to $d-2$ by proton-catalyzed reaction of the corresponding acid with 2,2,2- $\left[{ }^{2} \mathrm{H}\right]_{3}$ ethanol or 1,1,1- $\left[{ }^{2} \mathrm{H}\right]_{3}$-methanol, respectively.

$\left[{ }^{2} \mathrm{H}\right]_{2}$-3-Methylbutanol (d-7): 3-methylbutyric acid was reduced with lithium aluminum deuteride $\left(\mathrm{LiAlD}_{4}\right)$ to the alcohol $d-7$.

$\left[{ }^{2} \mathrm{H}\right]_{2}-3$-Methylbutyl acetate $(d-5)$ : The alcohol $d-7$ was esterified with acetic acid to the acetate $d-5$ analogously to $d-10$.

$\left[{ }^{2} \mathrm{H}\right]_{2}-E, E-2,4-D e c a d i e n a l(d-17):\left[{ }^{2} \mathrm{H}\right]_{2}$-2-octenal was synthesized starting from 2-octyn-1-ol in the same way as E-2-hexenal [8]. Via a Wittig reaction, $500 \mathrm{mg}(3.8 \mathrm{mmol})$ of $\left[{ }^{2} \mathrm{H}\right]_{2}$-2-octenal was converted with $1.3 \mathrm{~g}$ (3.8 mmol) (methoxycarbonylmethylene)triphenylphosphorane to $\left[{ }^{2} \mathrm{H}\right]_{2}$-methyl 2,4-decadienoate by stirring for $1 \mathrm{~h}$ in $50 \mathrm{~mL}$ of methanol at room temperature. After removal of the methanol, the residue was reconstituted in hexane and purified by chromatography on silica gel. $\left[{ }^{2} \mathrm{H}\right]_{2}$-Methyl 2,4-decadienoate was reduced with $76 \mathrm{mg}(2 \mathrm{mmol})$ of $\mathrm{LiAlH}_{4}$ by stirring for $1 \mathrm{~h}$ in dried tetrahydrofuran under reflux to the corresponding alcohol. The alcohol was then oxidized with pyridinium chromate to $d-\mathbf{1 7}$ analogously to $d-8$. Purification by chromatography on silica gel was performed as described in ref 14 and gave selectively the E,E-isomer in good yield $(>80 \%)$. 
$\left[{ }^{2} \mathrm{H}\right]_{3}$-Guaiacol (d-20): The method described in ref 16 was modified by using catechol instead of orcinol and dimethyl sulfate- $d_{6}$ as methylation reagent.

$\left[{ }^{2} \mathrm{H}\right]_{2}-6,10$-Dimethyl-1-undecene (d-9): 3,7-Dimethyloctanoic acid was reduced with $\mathrm{LiAlD}_{4}$ to $\left[{ }^{2} \mathrm{H}\right]_{2}-3,7$-octanol, which was transformed to $\left[{ }^{2} \mathrm{H}\right]_{2}-6,10$-dimethyl-1-undecene as described in ref 27 .

6,10-Dimethyl-1-undecene [9]: The unlabeled compound was synthesized in the same way as the labeled compound starting from 3,7-dimethyl-1-octanol.

Identification of 6,10-Dimethyl-1-undecene. For identification of the unknown peak the vacuum distillate of $1 \mathrm{~kg}$ of olive oil was fractionated by chromatography on silica gel. The unpolar fraction ( $100 \%$ pentane) was concentrated, and the unknown peak was purified by preparative gas chromatography. Preparative gas chromatography was performed with a Carlo Erba gas chromatograph (Typ GC8000 ${ }^{\text {Top }}$, ThermoQuest, Rodano, Italy) by using a packed column ( $3 \mathrm{~m}, 1 / 8$ in., FFAP phase). Identification was based on MS and ${ }^{1} \mathrm{H}$ NMR data: HRGC/MS(EI), m/z 55 (100), 97 (98), 69 (98), 70 (82), 57 (80), 70 (80), 43 (60), 71 (50), 83 (40), 105 (40), 111 (20), 154 (1.2), $182(1) ;{ }^{1} \mathrm{H}$ NMR (400 MHz, $\left.\mathrm{CD}_{2} \mathrm{Cl}_{2}\right) \delta 0.85(9 \mathrm{H}, \mathrm{d}, 6.1 \mathrm{~Hz})$, $1.30(8 \mathrm{H}, \mathrm{dd}, 18.5,9.0), 2.02(2 \mathrm{H}, \mathrm{m}), 4.91(1 \mathrm{H}, \mathrm{d}, 10.1 \mathrm{~Hz}), 4.99$ $(1 \mathrm{H}, \mathrm{d}, 17.2 \mathrm{~Hz}), 5.82(1 \mathrm{H}, \mathrm{m})$. The respective ${ }^{1} \mathrm{H}$ NMR spectrum is available as Supporting Information.

Concentrations of Deuterated Compounds. The concentrations of compounds $d-\mathbf{1}, d-\mathbf{2}, d-\mathbf{3}$, and $d-\mathbf{5}$ were determined by GCflame ionization detection (GC-FID) with ethyl butanoate as internal standard. Concentrations of $d-4, d-6-d-13, d-15, d-17$, and $d-19-d-21$ were determined with ethyl octanoate and $d-14, d-16, d-18$ with 3-methylbutyric acid as internal standard by GC-FID. GC-FID was performed with the apparatus and the capillaries for the respective compounds as described above. The response factors were determined by GC-FID analysis of mixtures consisting of known amounts of internal standard and of the unlabeled compounds under the same experimental conditions.

Statistical Analysis. Determinations were carried out in single analyses. However, reproducibility was evaluated by repetition of analysis of three samples three times. The mean coefficients of variation were in all cases $<20 \%$. Data were analyzed using The UnscramblerX 10.1 software package (Camo Inc., Oslo, Norway). Principal component analysis (PCA) was used to unravel the whole raw data set and to check for consistency. PCA is a nonsupervised pattern recognition tool, which facilitates the identification of hidden information and relations within the data set. For classification a partial least-squares discriminant (PLSDA) analysis was used. This is a supervised pattern recognition tool and therefore, as for all supervised methods, overfitting is in many cases a problem. Data pretreatment with activation functions based upon odor activity values was performed to avoid this problem. OAVs were calculated from quantification data divided by odor thresholds. OAVs were then scaled between 0 and 1 by using a sigmoid activation function where $a$ is the activation level and $g$ is the gain of the sigmoid activation curve:

$$
f(x)=\frac{1}{1+\mathrm{e}^{(a-x) \times g}}
$$

The parameters were chosen on the basis of considerations in terms of aroma development individual for each variable. Introducing such a priori knowledge for enhancing prediction models is described for ChemNets by Wang et al. ${ }^{17}$ The output of the activation functions was used for developing a partial least-squares discriminant model. The classes "extra virgin" and "non-extra virgin" were coded by the values 1 and -1 , respectively. Model optimization was performed on the basis of the correct classification rate of cross-validation. For crossvalidation the data set was randomly divided into three groups. Two groups were used for computing and the third one for validating the model. This procedure was performed three times so that each group was used for validation. Results of validation were used for calculating correct classification rates (in percent).

\section{RESULTS}

For the identification of the relevant odorants, the volatile fraction of selected olive oil samples was isolated by highvacuum distillation. Table 1 shows the results of GC-O analyses.

\section{Table 1. Potent Odorants in Olive Oil}

\begin{tabular}{|c|c|c|c|c|}
\hline \multirow[b]{2}{*}{ no. } & \multirow[b]{2}{*}{ odor description } & \multicolumn{2}{|c|}{$\begin{array}{l}\text { retention index } \\
\text { on }\end{array}$} & \multirow[b]{2}{*}{ compound $^{a}$} \\
\hline & & FFAP & OV1701 & \\
\hline 1 & fruity & 982 & 813 & ethyl isobutanoate \\
\hline 2 & fruity & 1063 & 907 & ethyl 2-methylbutanoate \\
\hline 3 & fruity & 1080 & 909 & ethyl 3-methylbutanoate \\
\hline 4 & green & 1101 & 877 & hexanal \\
\hline 5 & fruity & 1135 & 939 & 3-methylbutyl acetate \\
\hline 6 & grassy & 1160 & 886 & Z-3-hexenal \\
\hline 7 & malty & 1218 & 840 & 3-methylbutanol \\
\hline 8 & green, apple-like & 1239 & 956 & E-2-hexenal \\
\hline 9 & pungent & 1246 & 1213 & 6,10 -dimethyl-1-undecene ${ }^{b}$ \\
\hline 10 & banana-like & 1336 & 1076 & Z-3-hexenyl acetate \\
\hline 11 & leaf-like & 1397 & 965 & Z-3-hexenol \\
\hline 12 & citrus-like & 1409 & 1189 & nonanal \\
\hline 13 & leaf-like & 1418 & 974 & E-2-hexenol \\
\hline 14 & vinegary & 1468 & 799 & acetic acid \\
\hline 15 & paper-like, fatty & 1547 & 1275 & E-2-nonenal \\
\hline 16 & sweaty & 1645 & 996 & butyric acid \\
\hline 17 & deep-fried & 1838 & 1452 & $E, E-2,4$-decadienal \\
\hline 18 & sweaty & 1863 & 1186 & hexanoic acid \\
\hline 19 & medicinic & 1793 & 1299 & methyl salicylate \\
\hline 20 & phenolic, burnt & 1872 & 1224 & guaiacol \\
\hline 21 & sweet, winey & 1941 & 1271 & 2-phenylethanol \\
\hline
\end{tabular}

${ }^{a}$ All compounds, unless noted otherwise, were identified by comparison with the reference substances on the basis of the following criteria: RI on capillaries FFAP and OV-1701, mass spectra obtained by EI-MS and CI-MS (methane) and odor quality perceived at the sniffing port. ${ }^{b}$ This compound was isolated by preparative GC and identified by NMR and MS.

Compound identification was performed by comparing the following criteria with the reference substances: RI on FFAP and OV-1701 capillaries, mass spectra obtained by EI-MS, and odor quality perceived at the sniffing port. Auxiliary to the characteristic green and fruity odor notes, several off-flavorinducing aroma active compounds were found in the olive oils. All of these compounds had been already identified by several authors in olive oil samples of different qualities. $5,10,13,14,19,20,23$ Furthermore, the odor active compounds were quantified by HS-SPME-GC-MS with stable isotope labeled internal standards in our study. In addition acetone, ethyl acetate, and ethanol were quantified by dynamic headspace analysis. Figure 1 shows box plots of the quantification results. E-2-Hexenal (8), Z-3-hexenyl acetate (10), and Z-3-hexenol (11) showed the highest concentrations in most of the samples, whereas $E-2$ hexenal (8) achieved the maximum concentration (up to 20 $\mathrm{mg} / \mathrm{kg}$ ). This is in agreement with other studies. ${ }^{18}$ There are large differences in the aroma profile between extra virgin and non-extra virgin olive oils. Extra virgin olive oils showed higher concentrations of Z-3-hexenal (6), Z-3-hexenyl acetate (10), and Z-3-hexenol (11), whereas the concentrations of ethyl isobutanoate (1), ethyl 2-methylbutanoate (2), 3-methylbutanol 
Table 2. Selected Ions and Response Factors (rf) for Quantification

\begin{tabular}{|c|c|c|c|c|c|c|}
\hline no. & compound & ion $(m / z)$ & deuterated compound & ion $(m / z)$ & $\mathrm{rf}^{a}$ & $R^{2}$ \\
\hline 1 & ethyl isobutanoate ${ }^{b}$ & 117 & {$\left[2^{\prime}, 2^{\prime}, 2^{\prime}-{ }^{2} \mathrm{H}_{3}\right]$-ethyl isobutanoate } & 120 & 1.12 & 0.996 \\
\hline 2 & ethyl 2-methylbutanoate ${ }^{b}$ & 131 & {$\left[2^{\prime}, 2^{\prime}, 2^{\prime}-{ }^{2} \mathrm{H}_{3}\right]$-ethyl 2-methylbutanoate } & 134 & 0.75 & 0.996 \\
\hline 3 & ethyl 3-methylbutanoate ${ }^{b}$ & 131 & {$\left[2^{\prime}, 2^{\prime}, 2^{\prime}-{ }^{2} \mathrm{H}_{3}\right]$-ethyl 3-methylbutanoate } & 134 & 0.75 & 0.996 \\
\hline 4 & hexanal $^{b}$ & 101 & {$\left[2,2,3,3-{ }^{2} \mathrm{H}_{4}\right]$-hexanal } & 105 & 1.52 & 0.999 \\
\hline 5 & 3-methylbutyl acetate ${ }^{b}$ & 71 & {$\left[1^{\prime}, 1^{\prime}-{ }^{2} \mathrm{H}_{2}\right]-3$-methylbutyl acetate } & 73 & 1.13 & 0.992 \\
\hline 6 & Z-3-hexenal ${ }^{c}$ & 83 & {$\left[3,4-{ }^{2} \mathrm{H}_{2}\right]-Z-3$-hexenal } & 85 & 1.03 & 0.998 \\
\hline 8 & $E$-2-hexenal ${ }^{b}$ & 99 & {$\left[2,3-{ }^{2} \mathrm{H}_{2}\right]-E-2$-hexenal } & 101 & 1.09 & 0.998 \\
\hline 9 & 6,10-dimethyl-1-undecene & 97 & {$\left[4,4{ }^{2} \mathrm{H}_{2}\right]-6,10$-dimethyl-1-undecene } & 99 & 0.86 & 0.996 \\
\hline 10 & Z-3-hexenyl acetate ${ }^{b}$ & 82 & {$\left[3^{\prime}, 4^{\prime}-{ }^{2} \mathrm{H}_{2}\right]-Z-3-$ hexenyl acetate } & 84 & 1.32 & 0.997 \\
\hline 11 & Z-3-hexenol ${ }^{b}$ & 82 & {$\left[3,4-{ }^{2} \mathrm{H}_{2}\right]-Z-3$-hexenol } & 84 & 1.68 & 0.996 \\
\hline 12 & nonanal $^{b}$ & 143 & {$\left[2,2,3,3-{ }^{2} \mathrm{H}_{4}\right]$-nonanal } & 147 & 1.78 & 0.999 \\
\hline 13 & $E$-2-hexenol ${ }^{b}$ & 82 & {$\left[2,3-{ }^{2} \mathrm{H}_{2}\right]-E-2$-hexenol } & 84 & 1.25 & 0.999 \\
\hline 14 & 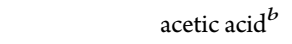 & 61 & {$\left[{ }^{13} \mathrm{C}_{2}\right]$-acetic acid } & 63 & 0.82 & 0.995 \\
\hline 16 & butyric acid $b$ & 89 & {$\left[2,3-{ }^{2} \mathrm{H}_{2}\right]$-butyric acid } & 91 & 2.80 & 0.995 \\
\hline 17 & $E, E-2,4$-decadienal ${ }^{b}$ & 153 & {$\left[4,5-{ }^{2} \mathrm{H}\right]_{2}-E, E-2,4-$ decadienal } & 155 & 1.26 & 0.999 \\
\hline 18 & hexanoic acid $b$ & 117 & {$\left[2,2,3,3-{ }^{2} \mathrm{H}_{4}\right]$-hexanoic acid } & 121 & $4.12^{d}$ & 0.997 \\
\hline 19 & methyl salicylate ${ }^{c}$ & 152 & {$\left[1^{\prime}, 1^{\prime}, 1^{\prime}-{ }^{2} \mathrm{H}_{3}\right]$-methyl salicylate } & 155 & 1.31 & 0.999 \\
\hline 20 & guaiacol $^{c}$ & 124 & {$\left[1^{\prime}, 1^{\prime}, 1^{\prime}-{ }^{2} \mathrm{H}_{3}\right]$-guaiacol } & 127 & 1.14 & 0.999 \\
\hline 21 & 2-phenylethanol ${ }^{b}$ & 105 & {$\left[1,1-{ }^{2} \mathrm{H}_{2}\right]-2$-phenylethanol } & 107 & 1.00 & 0.998 \\
\hline 22 & acetone $e^{c}$ & 58 & {$\left[1,3-{ }^{13} \mathrm{C}_{2}\right]$-acetone } & 60 & $1.00^{e}$ & \\
\hline 23 & ethyl acetate ${ }^{c}$ & 88 & {$\left[1,2-{ }^{13} \mathrm{C}_{2}\right]$-ethyl acetate } & 90 & $1.00^{e}$ & \\
\hline 24 & ethanol $^{c}$ & 46 & {$\left[2,2,2-{ }^{2} \mathrm{H}_{3}\right]$-ethanol } & 49 & $1.00^{e}$ & \\
\hline
\end{tabular}

${ }^{a}$ The relative abundances of the ions of the labeled and unlabeled compound were recorded (details under Materials and Methods). ${ }^{b} \mathrm{CI}-\mathrm{MS} .{ }^{c} \mathrm{EI}-$ MS. ${ }^{d}$ The high response factor can be explained by a variable deuteration level (2-4),. ${ }^{e}$ These response factors were set to 1 .

(7), E-2-nonenal, E,E-2,4-decadienal (17), butyric acid (16), hexanoic acid (18), 2-phenylethanol (21), and guaiacol (20) were higher in olive oils with off-flavor. The quantitative data of 21 aroma active compounds and ethanol, ethyl acetate, and acetone analyzed in 95 different olive oil samples are compiled in Table S1 of the Supporting Information.

Principal component analysis (PCA) was carried out to get structured information about the raw data. Figure 2 shows the loadings and scores plot of the first two principal components (PC). In the scores plot (Figure 2a), a suitable separation of extra virgin olive oils (left side) and non-extra virgin olive oils (right side) can be recognized. The separation is based on different variables, which are shown in the loadings plot (Figure $2 \mathrm{~b}$ ). The compounds on the right side are typical for non-extra virgin olive oils. On the one hand, there are compounds such as E-2-nonenal (15) and E,E-2,4-decadienal (17) for which concentrations increase during fat oxidation; on the other hand, there are compounds that are typical indicators for microbial spoilage (e.g., guaiacol (20), 3-methylbutanol (7), acetic acid (14)). ${ }^{19,20,26}$ The extra virgin olive oils are mainly characterized by higher contents of the green-smelling odor compounds Z-3-hexenal (6), Z-3hexenol (10), and Z-3-hexenyl acetate (11), which are synthesized within the lipoxygenase (LOX) pathway and for which concentrations are dependent on the olive variety, the ripeness of the fruits, and the processing parameters. ${ }^{1,21,22}$ 6,10-Dimethyl-1undecene (9) shows no significant correlation with olive oil quality. Variance in concentrations between the samples depends probably on differences in variety and origin of the olives. ${ }^{23}$ Similar behavior is expected for methyl salicylate (19). The first two PCs explain together only $35 \%$ of the total variance in the data set. Hence, a lot of nonrelevant information for the classification problem is included in the data set. More selective extraction of the relevant information should be realized by a supervised pattern recognition tool, which will be described in the following.

Classification of the oil samples as extra virgin and non-extra virgin olive oils was carried out by evaluation of quantification and sensory evaluation data by PLS-DA. A value of 1 was assigned to extra virgin olive oils and a value of -1 to non-extra virgin olive oils. A classification model based on all quantitative data except compounds 9 and 19 has a correct classification rate of $82 \%$. Most of the misclassifications (14 of 16) were in the group of the non-extra virgin olive oils. A possible explanation for these misclassifications of non-extra virgin olive oils is the high variance in the quantification data caused by sample with extreme intensive off-flavors, and the excess of nonrelevant information (the noise) in the data set for the classification problem. To reduce the noise, only quantification data of compounds that have an influence on olive oil aroma should be used. Reducing the influence of extreme values is feasible by scaling the quantification data. Both intentions could be achieved by calculating OAVs and transforming these with individual activation functions as described above using coefficients $a$ and $g$ for the different compounds shown in Table 3. For the variables 1, 2, 4, and 14, which have $a$ values of $>1$, the 75 th percentile of the OAVs in the group of the extra virgin olive oil was set as activation level. OAVs showed that only the compounds listed in Table 3 have an influence on olive oil aroma. Additionally, the sum of OAVs of the green-fruitysmelling flavor compounds Z-3-hexenal (6), E-2-hexenal (8), Z-3hexenyl acetate (10), and Z-3-hexenol (11) results in a classfification model with a better classification rate of $88 \%$. Four extra virgin olive oils and seven non-extra virgin olive oils were misclassified. To evaluate the sensory impact of these selected aroma compounds on the off-flavor in our study, model oils containing only a limited number of aroma active compounds were sensory evaluated. Odor compounds were selected by their 


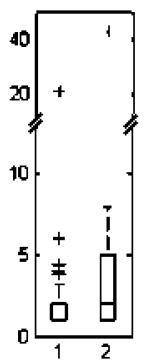

1
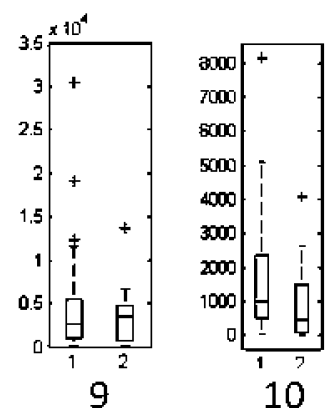

10
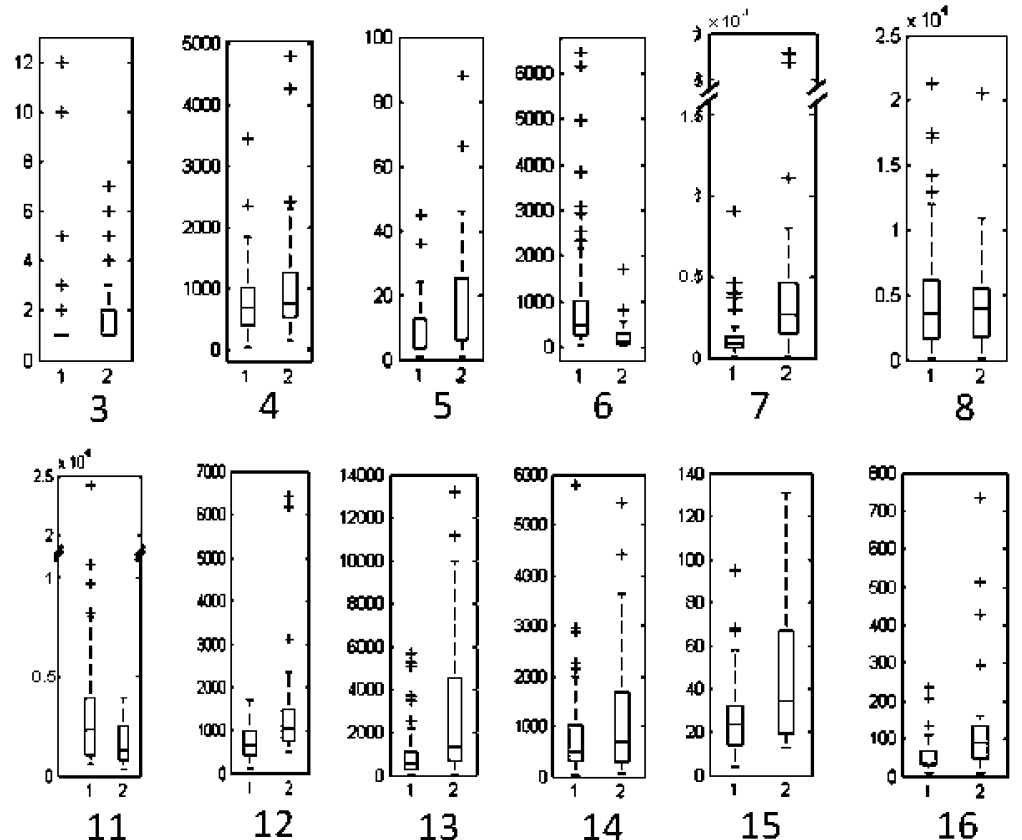

15

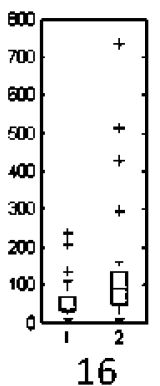

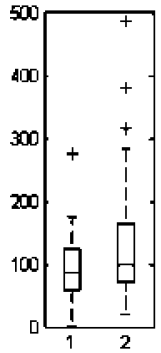

17

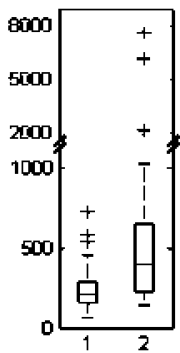

18

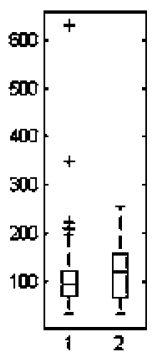

19

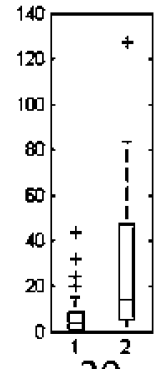

20

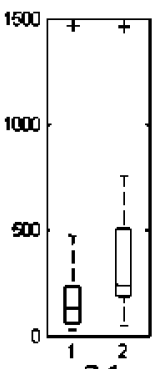

21

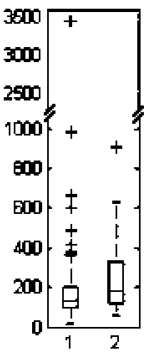

22

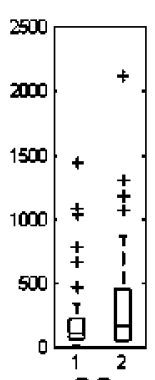

23

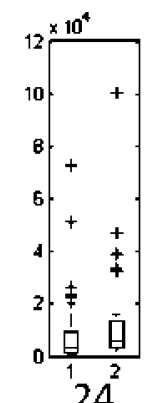

24

Figure 1. Box plots of the quantification results. Group 1, extra virgin; group 2, non-extra virgin. All amounts in $\mu \mathrm{g} / \mathrm{kg}$. (Compound numbers are the same as in Table 2.)

OAVs and their influence as variable in PCA and PLS-DA. Table 4 shows compositions of the models and the related sensory results. The off-flavor "rancid" can be simulated by two different kinds of models. The first model is dominated by E,E-2,4-decadienal (17), whereas the second is characterized by a high content of hexanal (4) and hexanoic acid (18). The third model induces the off-flavor "fusty". Guaiacol (20), 3-methylbutanol (7), and 2-phenylethanol (21) are the aroma compounds that are important for the fusty flavor. In the last model the esters ethyl isobutanoate (1) and ethyl 2-methylbutanoate (2) in combination with acetic acid (14) and butyric acid (16) are responsible for the vinegarywiney off-flavor.

\section{DISCUSSION}

Olive oils of different qualities show high differences in the aroma profile. The aroma of olive oils belonging to the best quality class (extra virgin) is dominated by the green-smelling odorants Z-3-hexenal (6), E-2-hexenal (8), Z-3-hexenyl acetate (10), and Z-3-hexenol (11). These compounds have their origin in the lipoxygenase (LOX) pathway and are characteristic for olive oil made of healthy and sound green olives. ${ }^{4}$ However, odorants that are related to off-flavors are also found in smaller amounts in these oils.

Olive oils with off-flavor showed lower amounts of the greensmelling compounds and higher concentrations of off-flavor- inducing odorants instead. These can be divided into two different groups. The aldehydes 4, 15, 17, and hexanoic acid 18 are produced during fat oxidation. The esters 1, 2, 3, 5, and 3-methylbutanol (7) are produced by Pseudomonas and Clostridium species. Fermentation of carbohydrates by Acetobacter species results in acetic acid, ethanol, and ethyl acetate. ${ }^{20}$ The potent aroma compound guaiacol (20) is a spoilage product of different microbes formed by decarboxylation of vanillic acid. ${ }^{25}$

These results indicate that a classification of olive oils based on the flavor profile should be possible. Several authors developed classification models by following this approach. Angerosa et al. applied an artificial neural network on headspacegas chromatographic results for predicting panel tests scores. ${ }^{8}$ Input data were 114 chromatographic peaks. Most of the peaks were not identified, and peaks were not correlated to their potential aroma activity. As a result, it is hard to verify which compounds had the highest influence on the prediction model and which of these compounds are responsible for the olive oils aroma, too.

Servili et al. studied relationships between chemical headspace composition and sensory data using partial least-squares regressions on log-transformed analysis data. ${ }^{24}$ Best prediction results were achieved for the sensory attributes "vinegar" and "cut grass". Prediction of "vinegar" was performed mainly on the basis of amounts of ethyl acetate, 1-butanol, and acetic acid, 


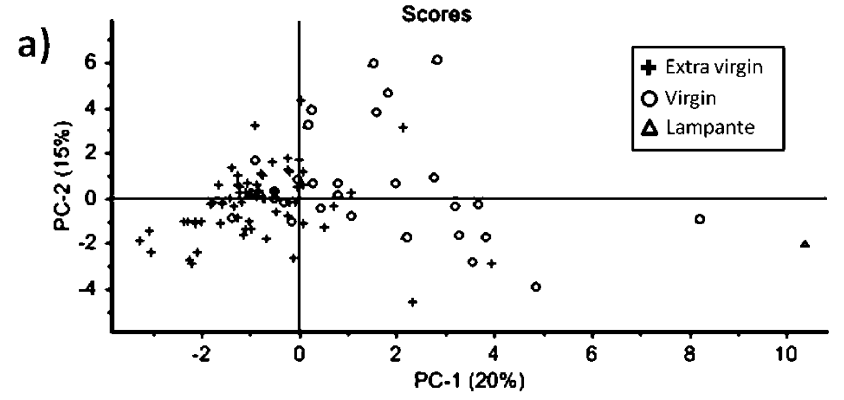

b)

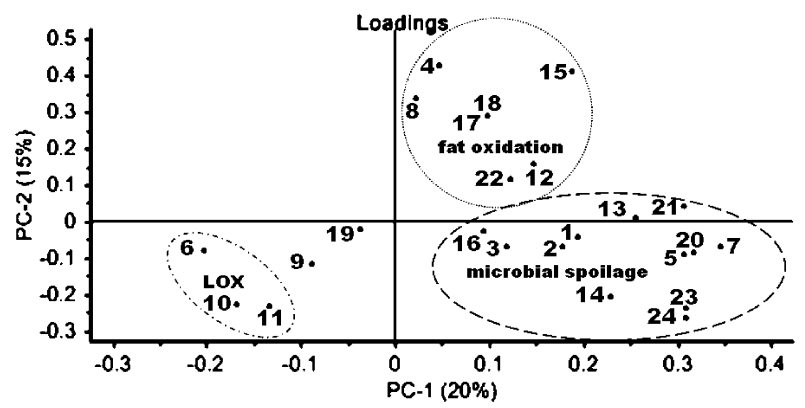

Figure 2. Principal component analysis (PCA) of the raw data: (a) scores plot (separation of extra virgin olive oils (left side) and nonextra virgin olive oils (right side)); (b) loadings plot (differentiation between off-flavors and the green-fruity attribute). Compound numbers are the same as in Table 2. LOX, green-smelling compounds of lipoxygenase pathway.

Table 3. Odor Thresholds and Coefficients for Activation Function

\begin{tabular}{llccc}
\multicolumn{1}{c}{ volatile compound } & no. & odor threshold $^{a}$ & $a$ & $g$ \\
ethyl isobutanoate $^{b}$ & $\mathbf{1}$ & 1.2 & 3 & 10 \\
ethyl 2-methylbutanoate $^{b}$ & $\mathbf{2}$ & 0.7 & 4 & 10 \\
hexanal $^{b}$ & $\mathbf{4}$ & 300 & 3 & 10 \\
3-methylbutanol $^{b}$ & $\mathbf{7}$ & 100 & 1 & 1 \\
acetic acid $^{b}$ & $\mathbf{1 4}$ & 124 & 8 & 1 \\
butyric acid $^{c}$ & $\mathbf{1 6}$ & 135 & 1 & 10 \\
E,E-2,4-decadienal $^{b}$ & $\mathbf{1 7}$ & 180 & 1 & 10 \\
hexanoic acid $^{c}$ & $\mathbf{1 8}$ & 700 & 1 & 10 \\
guaiacol $^{b}$ & $\mathbf{2 0}$ & 16 & 1 & 10 \\
2-phenylethanol $^{b}$ & $\mathbf{2 1}$ & 211 & 1 & 10 \\
& & & & \\
Z-3-hexenal $^{b}$ & $\mathbf{6}$ & 1.7 & & \\
E-2-hexenal $^{b}$ & $\mathbf{8}$ & 424 & & \\
Z-3-hexenyl acetate $^{b}$ & $\mathbf{1 0}$ & 200 & & \\
Z-3-hexenol $^{b}$ & $\mathbf{1 1}$ & 1100 & & \\
sum $^{d}$ & & & &
\end{tabular}

${ }^{a}$ Odor thresholds were determined orthonasally. All amounts are in $\mu \mathrm{g} / \mathrm{kg} .{ }^{b}$ Reference $4 .{ }^{c}$ Reference ${ }^{12} .{ }^{d}$ Sum of OAVs of Z-3-hexenal, E-2-hexenal, Z-3-hexenyl acetate, and Z-3-hexenol.

although the last one shows a lower influence. Because input data were only peak areas, the contribution of these compounds to the olive oil flavor could not been investigated. However, both ethyl acetate and 1-butanol have high odor thresholds, so that they cannot be responsible for the off-flavor "vinegar". The sensory attribute "cut grass" was predicted using mainly unidentified peaks. Whether these peaks were aroma active
Table 4. Aroma Compound Concentrations in Model Oils

\begin{tabular}{|c|c|c|c|c|c|}
\hline oil & compound & no. & $C(\mu \mathrm{g} / \mathrm{kg})$ & $\mathrm{OAV}^{a}$ & sensory result ${ }^{b}$ \\
\hline \multirow[t]{3}{*}{1} & $E, E-2,4$-decadienal & 17 & 450 & 3 & rancid 2.6 \\
\hline & hexanoic acid & 18 & 370 & $<1$ & \\
\hline & hexanal & 4 & 1030 & 3 & \\
\hline \multirow[t]{3}{*}{2} & $E, E-2,4$-decadienal & 17 & 130 & $<1$ & rancid 3.1 \\
\hline & hexanoic acid & 18 & 6390 & 9 & \\
\hline & hexanal & 4 & 4990 & 17 & \\
\hline \multirow[t]{4}{*}{3} & 3-methylbutanol & 7 & 7590 & 76 & fusty 3.9 \\
\hline & acetic acid & 14 & 1990 & 16 & \\
\hline & 2-phenylethanol & 21 & 1550 & 7 & \\
\hline & guaiacol & 20 & 100 & 6 & \\
\hline \multirow[t]{4}{*}{4} & $\begin{array}{l}\text { ethyl 2- } \\
\text { methylbutanoate }\end{array}$ & 2 & 120 & 167 & $\begin{array}{l}\text { winey-vinegary } \\
1.9\end{array}$ \\
\hline & ethyl isobutanoate & 1 & 60 & 50 & \\
\hline & acetic acid & 14 & 5060 & 41 & \\
\hline & butyric acid & 16 & 540 & 4 & \\
\hline
\end{tabular}

${ }^{a}$ Quotient of concentration and odor thresholds reported in Table 3. ${ }^{b}$ Evaluation on a scale from 0 to 10 .

smelling like cut grass or not was not studied by gas chromatography with olfactometric detection.

García-González et al. developed a method for distinguishing olive pastes producing virgin olive oil from those which gave lampante olive oils. ${ }^{10}$ Classification was performed by stepwise linear discriminant analysis (SLDA) based on six volatile compounds: acetic acid, octane, methyl benzene, E-2-hexenal, hexyl acetate, and 3-methyl-1-butanol. The first three are related to undesirable sensory attributes, and the second three are related to high-quality olive oil aroma. The choice of the variables is not consistent. Both octane and methylbenzene are compounds produced in the advanced stage of spoilage and have relatively high odor thresholds. The odor descriptions of these hydrocarbons (alkane, solvent-like) do not match the usual off-flavors. There are several other aroma compounds with lower odor thresholds that are produced even in the beginning of spoilage and for which odor descriptions are typical for the usual offflavors. One of these compounds is 3-methylbutanol (7), which is related to good quality in the study. However, no explanation could be given by the authors. In summary, it can be stated that the odor quality and the odor thresholds of the compounds should play an important role in selection of the variables for classification. These conditions were not achieved in the past.

In this work classification of olive oils is performed only on the basis of compounds that are directly responsible for the offflavors. Only odorants that show higher concentrations than their odor thresholds have an influence on the aroma. Therefore, the critical factor for classification should be whether the concentration of an off-flavor-inducing odorant is higher than the odor threshold or not. To realize this, OAVs for all aroma active compounds were calculated from the quantification data and transformed by activation functions. The activation functions weight down OAVs to a smaller extent than the activation level $a$ and those higher than $a$ are weighted up. The activation level $a$ is set to 1 and the gain $g$ is set to 10 for most compounds. The influence on the olive oil quality of the compounds increases dramatically if the concentration is higher than the odor threshold. This fact is taken into account by the activation function. 
However, there are compounds such as hexanal and the esters 1 and $\mathbf{2}$ for which aroma quality and therefore their influence on the olive oil quality change at higher concentrations. The odor description of hexanal is, in lower amounts, green, and in higher amounts, unpleasantly sebaceous. To take this into account the activation level $a$ in the activation function was set to 3 for hexanal. This means that only concentrations higher than 3 times the odor threshold of hexanal $(3 \times 300 \mu \mathrm{g} / \mathrm{kg}=900 \mu \mathrm{g} / \mathrm{kg})$ have a negative influence on the olive oil quality. The fruity esters $\mathbf{1}$ and $\mathbf{2}$ and acetic acid $\mathbf{1 4}$ are other examples that OAV could not be the only criterion for the influence of an aroma compound on the aroma. At lower OAVs these compounds are part of the aroma of extra virgin olive oils and are responsible for a ripe and fruity aroma. Only at higher OAVs they induce off-flavor and remind one of overripe or spoiled fruits. For this reason the activation levels are set to 3,4 , and 8 , respectively, which indicate that these compounds induced off-flavors at concentrations 3,4 , or 8 times higher than the odor thresholds. To take into account that high odor activity values of the greensmelling odorants can mask potentially present off-flavors, the sum of the OAVs of the green-smelling odorants was used as an additional variable. The activation level $a$ was set to 180 , which conforms to the 75th percentile of the values of the non-extra virgin olive oils. The gain $g$ was set to 1 to get a smoother slope in the middle range of the values.

The different influence of the odorants on the olive oil quality and possible interactions of the compounds with each other are taken into account by the PLS-DA.

A new concept for the quality evaluation is introduced by using OAVs transformed by individual activation functions as variables for PLS-DA. The described method allows introducing previous knowledge of the variables and their relationships. This can help to avoid overfitting and to increase model efficiency. A classification method for the differentiation of extra virgin and non-extra virgin olive oils based on this concept was successfully set up.

The results of the sensory evaluation of the model oils show that reference oils with defined off-flavors can be produced by mixing the odorants listed in Table 4. In future works the concentration dependency should be evaluated. Furthermore, interactions with other aroma compounds, especially the greensmelling compounds, should be investigated, which were not regarded in the model mixtures.

First investigations in the reconstitution of olive oil offflavors by mixing a limited number of aroma active compounds indicate that this is a possible way to create oil samples with standardized off-flavors. These model oils could be used to train sensory panels.

\section{ASSOCIATED CONTENT}

\section{S Supporting Information}

Quantification data of 24 analytes and sensory evaluated data for all 95 olive oils; ${ }^{1} \mathrm{H}$ NMR spectrum of 6,10-dimethyl-1undecene in dichloromethane- $d_{2}$. This material is available free of charge via the Internet at http://pubs.acs.org.

\section{AUTHOR INFORMATION}

\section{Corresponding Author}

*Phone: (+49) 202 4393457. Fax: (+49) 202 4393073. E-mail: hayen@uni-wuppertal.de.

\section{ACKNOWLEDGMENTS}

We are grateful to the Swiss Olive Oil Panel for the sensory evaluation of samples.

\section{ABBREVIATIONS USED}

PCA, principal component analysis; PLS-DA, partial least-squares discriminant analysis; HS-SPME, headspace solid phase microextraction; OAV, odor activity value; GC-O, gas chromatographyolfactometry.

\section{REFERENCES}

(1) Angerosa, F.; Servili, M.; Selvaggini, R.; Taticchi, A.; Esposto, S.; Montedoro, G. Volatile compounds in virgin olive oil: occurrence and their relationship with the quality. J. Chromatogr. A 2004, 1-2, 17-31.

(2) Revised method for the organoleptic assessment of virgin olive oil, decision DEC-21/95-V/2007, Madrid Spain, 2007.

(3) García-González, D. L.; Aparicio, R. Research in olive oil: Challenges for the near Ofuture. J. Agric. Food Chem. 2010, 58, 1256912577.

(4) Angerosa, F. Influence of volatile compounds on virgin olive oil quality evaluated by analytical appraches and sensor panels. Eur. J. Lipid Sci. Technol. 2002, 104, 639-660.

(5) Kalua, C. M.; Allen, M. S.; Bedgood, D. R. JR; Bishop, A. G.; Prenzler, P. D.; Robards, K. Olive oil volatile compounds, flavour development and quality: A critical review. Food Chem. 2007, 100, 273-286.

(6) Vichi, S.; Guadayol, J. M.; Caixach, J.; López-Tamames, E.; Buxaderas, S. Comparative study of different extraction techniques for the analysis of virgin olive oil aroma. Food Chem. 2007, 105, 11711178.

(7) Steinhaus, M.; Fritsch, H. T.; Schieberle, P. Quantitation of (R)- and (S)-linalool in beer using solid phase microextraction (SPME) in combination with a stable isotope dilution assay (SIDA). J. Agric. Food Chem. 2003, 51, 7100-7105.

(8) Angerosa, F.; Di Giacinto, L.; Vito, R.; Cumitini, S. Sensory evaluation of virgin olive oils by artificial neural network processing of dynamic head-space gas chromatographic data. J. Sci. Food Agric. 1996, $72,323-328$.

(9) Garrido-Delgado, R.; Mercader-Trejo, F.; Sielemann, S.; Bruyn, W.; de; Arce, L.; Valcárcel, M. Direct classification of olive oils by using two types of ion mobility spectrometers. Anal. Chim. Acta 2011, 696, 108-115.

(10) Garcia-Gonzalez, D. L.; Noelia, Tena; Aparicio, R. Characterization of olive paste volatiles to predict the sensory quality of virgin olive oil. Eur. J. Lipid Sci. Technol. 2007, 109, 663-672.

(11) Esterbauer, H. Autoxidation of methyl linoleate in water III. Separation of water soluble reaction products by chromatography. Fette, Seifen, Anstrichm. 1968, 70, 1-4.

(12) Guth, H.; Grosch, W. 3-Methylnonane-2,4-dione - An intense odour compound formed during flavour reversion of soya-bean oil. Fett Wiss. Technol. 1989, 91, 225-230.

(13) Reiners, J.; Grosch, W. Odorants of virgin olive oils with different flavor profiles. J. Agric. Food Chem. 1998, 46, 2754-2763.

(14) Guth, H.; Grosch, W. Quantitation of potent odorants of virgin olive oil by stable-isotope dilution assays. JAOCS 1993, 5, 513-518.

(15) Guth, H.; W. Grosch, W. Deterioration of soya-bean oil: Quantification of primary flavour compounds using a stable isotope dilution assay. Lebensm.-Wiss. u. Technol 1990, 23, 513-522.

(16) Mirrington, R. N.; Feutrill, G. I. Orcinol monoethyl ether. Org. Synth. 1988, 6, 859 .

(17) Wang, Z.; Hwang, J.-N.; Kowalski, B. R. ChemNets: Theory and application. Anal. Chem. 1995, 67, 1497-1504.

(18) Kandylis, P.; Vekiari, A. S.; Kanellaki, M.; Grati Kamoun, N.; Msallem, M.; Kourkoutas, Y. Comparative study of extra virgin olive oil flavor profile of Koroneiki variety (Olea europaea var. Microcarpa alba) cultivated in Greece and Tunisia during one period of harvesting. LWT - Food Sci. Technol. 2011, 44, 1333-1341. 
(19) Vichi, S.; Romero, A.; Tous, J.; Tamames, E. L.; Buxaderas, S. Determination of volatile phenols in virgin olive oils and their sensory significance. J. Chromatogr. A 2008, 1211, 1-7.

(20) Morales, M. T.; Luna, G.; Aparicio, R. Comparative study of virgin olive oil sensory defects. Food Chem. 2005, 91, 293-301.

(21) Aparicio, R.; Morales, M. T. Characterization of olive ripeness by green aroma compounds of virgin olive oil. J. Agric. Food Chem. 1998, 46, 1116-1122.

(22) Di Giovacchino, L.; Sestili, S.; Di Vincenzo, D. Influence of olive processing on virgin olive oil quality. Eur. J. Lipid Sci. Technol. 2002, 104, 587-601.

(23) Bortolomeazzi, R.; Berno, P.; Pizzale, L.; Conte.; Lanfranco, S. Sesquiterpene, alkene and alkane hydrocarbons in virgin olive oils of different varieties and geographical origins. J. Agric. Food Chem. 2001, 49, 3278-3283.

(24) Servili, M.; Conner, J. M.; Piggott, J. R.; Withers, S. J.; Paterson, A. Sensory characterisation of virgin olive oil and relationship with headspace composition. J. Sci. Food Agric. 1995, 67, 61-70.

(25) Vichi, S.; Romero, A.; Gallardo-Chacón, J.; Tous, J.; LópezTamames, E.; Buxaderas, S. Influence of olives' storage conditions on the formation of volatile phenols and their role in off-odor formation in the oil. J. Agric. Food Chem. 2009, 57, 1449-1455.

(26) Vichi, S.; Pizzale, L.; Conte, L. S.; Buxaderas, S.; LopezTamames, E. Solid-phase microextraction in the analysis of virgin olive oil volatile fraction: Modifications induced by oxidation and suitable markers of oxidative status. J. Agric. Food Chem. 2003, 51, 6564-6571.

(27) Huo, S.; Negishi, E.-I. A convenient and asymmetric protocol for the synthesis of natural products containing chiral alkyl chains via Zr-catalyzed asymmetric carboalumination of alkenes. Synthesis of phytol and vitamins E and K. Org. Lett. 2001, 3, 3253-3256. 